\author{
K. Zaleski, A. Skoczylas* \\ Lublin University of Technology, Faculty of Mechanical Engineering, Department of \\ Production Engineering, Nadbystrzycka 36, 20-618 Lublin, Poland \\ *a.skoczylas@pollub.pl
}

\title{
EFFECT OF SLIDE BURNISHING ON THE SURFACE LAYER AND FATIGUE LIFE OF TITANIUM ALLOY PARTS
}

\begin{abstract}
The paper presents the results of a study investigating the effect of slide burnishing on the surface roughness, surface layer microhardness and fatigue life of Ti6Al2Mo2 $\mathrm{Cr}$ titanium alloy parts. The burnishing process was performed with the use of a diamond tip tool. Different machining fluids were used as machining media. Prior to burnishing, the samples were subjected to turning. The burnishing process led to reduced surface roughness (average roughness Ra decreased by 3.5 times and roughness $\mathrm{Rz}$ decreased by 2.5 times) as well as increased surface layer microhardness (microhardness maximum increase by $12 \%$ ) and fatigue life of the tested parts. A relationship between the machining medium and the burnishing effects was also observed. The addition of a surface-active polymethyl methacrylate solution to the machining medium led to an increase in the surface layer microhardness and fatigue life of the workpiece.
\end{abstract}

Keywords: slide burnishing, fatigue life, titanium alloy, surface layer

\section{INTRODUCTION}

Titanium alloys are characterized by their high strength-to-weight ratio, resistance to corrosion and high temperatures. Due to these properties, titanium alloys are valuable structural materials that are used, among others, in the aerospace, ship building and chemical industries. Machine components made of these alloys are often exposed to variable loads during operation. One of the methods for increasing fatigue strength of machine parts is burnishing, which can be static or dynamic. Static burnishing (roller or slide burnishing) is characterized by relatively constant impact force of the ball or the burnishing roller on the workpiece. In the dynamic burnishing process, also known as shot peening, the shot impacts the workpiece surface with force sufficient to create plastic deformation. Static burnishing and shot peening cause changes in the workpiece surface roughness, make the surface layer strainhardened and generate compressive residual stresses [1, 2, 3, 4]. These changes in surface 
layer properties are associated with higher density of defects in the crystalline structure, as confirmed by the studies performed by annihilation techniques[5, 6].

Machine parts made of titanium alloys are often shot-peened. Shot peening enables to increase the part's fatigue life by several times, this increase being dependent on the shot energy and impact density [7]. Higher fatigue strength of pressure-cast titanium alloys was obtained by shot peening using zirconia shot with a diameter of $500 \mu \mathrm{m}$ [8]. The authors of the study [9] have found that the use of shot peening increases the fatigue strength of Ti-6Al$4 \mathrm{~V}$ alloy samples, at room temperature and at $150^{\circ} \mathrm{C}$ alike. The fact that shot peening leads to higher fatigue strength and wear resistance of parts has also been observed for carburized Ti6Al-4V [1]. By choosing appropriate technological conditions of shot peening, one can also reduce the fretting wear of titanium alloys $[10,11]$. It has been found that shot peening enhances the surface layer properties and corrosion resistance of titanium alloy powder parts produced by DMLS [12].

Compared to shot peening, the roller burnishing process ensures a higher depth of surface layer hardening of titanium alloys. For example, after the rolling burnishing of $\mathrm{Ti}-2.5 \mathrm{Cu}$ alloy, a strain-hardened layer was obtained, which was about 3 times deeper than the layer produced by shot peening [13]. Effects of roller burnishing depend to a large extent on technological conditions, as confirmed by the investigation of TiAl6Nb7 alloy [14] and tool design [15]. The authors of the study [16] have found that the combined use of roller burnishing and nitriding on the samples made of titanium alloy Ti-6Al-5Mo-5V-1, $5 \mathrm{Cu}-1 \mathrm{Fe}$ (according to Russian standards VT22) leads to higher wear resistance of these samples in contact with $\mathrm{Cu}-10 \mathrm{Al}-4 \mathrm{Ni}-4 \mathrm{Fe}$ counter-samples. The works $[17,18]$ present the results of investigations on the effect of roller burnishing parameters on the surface roughness and tribological wear of Ti-6Al-4V parts. It has also been found that results of the roller burnishing process depend on the pre-burnishing condition of the surface layer [19].

Due to small tool radius, slide burnishing is characterized by the presence of low forces, which enables the machining of low-rigidity parts. Previous works have investigated slide burnishing for materials such as steel, cast iron, aluminum alloys and magnesium alloys. Slide burnishing is used largely in aerospace, automotive and other industries [20]. The working part of the slide burnishing tool usually comes in the shape of a spherical cap and is often made of diamond or ceramic [21], which makes it possible to burnish hard materials [21]. For example, slide burnishing can be used to enhance the wear resistance of cold work tool steels (approx.60 HRC) [22]. The authors of the work [23] report the results of a study on the effects of burnishing technological conditions on the corrosion resistance of X6CrNiMoTi17-12-2 stainless steel. In turn, the work [24] presents the results of a study investigating the effect of slide burnishing parameters on the surface structure geometry of AZ91 magnesium alloy parts.

Burnishing can be performed with the use of different media. If a medium contains surface active additives, then mechanical properties of the processed material change, which affects results of the burnishing process $[25,26]$.

The aim of this study was to determine the effect of slide burnishing performed using different media on the surface roughness, surface layer microhardness and fatigue life of Ti6Al2Mo2Cr parts.

\section{MATERIALS AND METHODS}

Ti6Al2Mo2Cr samples were investigated in this study. This alloy is used for manufacturing parts that are exposed to high and variable loads during operation. The 
chemical composition of Ti6Al2Mo2Cr is given in Tab. 1 (as per the technical specification). The experiments were performed on thin-walled ring-shaped samples, the dimensions of which are given in Fig. 1.

Table 1. Composition of Ti6Al2Mo2Cr titanium alloy

\begin{tabular}{lcccccccc}
\hline Element & $\mathrm{Al}$ & $\mathrm{Mo}$ & $\mathrm{Cr}$ & $\mathrm{Si}$ & $\mathrm{Fe}$ & $\mathrm{C}$ & $\mathrm{N}$ & $\mathrm{Ti}$ \\
\hline Mass fraction (\%) & 6.1 & 2.2 & 1.3 & 0.25 & 0.42 & 0.05 & 0.04 & balance \\
\hline
\end{tabular}

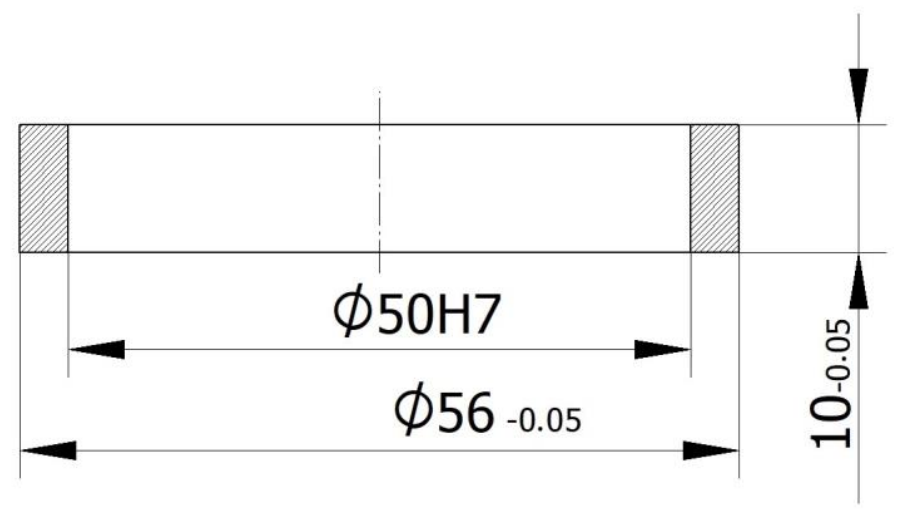

Fig. 1. Sample for testing

The outer cylindrical surface of the samples (to be slide burnished) was machined by turning using a tool provided with a plate made of sintered carbide K10. The following cutting parameters were applied: the cutting depth $-a_{p}=1 \mathrm{~mm}$, the feed rate $-f_{r}=0.1 \mathrm{~mm} / \mathrm{rev}$, the cutting velocity $-\mathrm{v}_{\mathrm{c}}=70 \mathrm{~m} / \mathrm{min}$.

Thin-walled Ti6Al2Mo2Cr samples were subjected to slide burnishing on an engine lathe, as shown schematically in Fig. 2. A sample (2) is mounted on a mandrel (1) which performs rotational motion with a velocity $n$. A burnishing tool (4), which is clamped to said sample by a spring (5) with a force $F$, performs a feed motion $f$. Said tool has a diamond tip (3) in the shape of a spherical cap having the radius $r$ of $2.5 \mathrm{~mm}$. A view of the stand for slide burnishing experiments is shown in Fig. 3 .

The slide burnishing process was performed with the use of the following liquid lubricants (media):

- Mobile Vactra ${ }^{\mathrm{TM}}$ Oil No. 2,

- oil with a polymethyl methacrylate solution $(0.5 \%)$,

- $\quad$ oil with molybdenum disulfide $(0.5 \%)$,

- oil with polymethyl methacrylate $(0.5 \%)$ and molybdenum disulfide $(0.5 \%)$ solutions,

- EcoEm-1 emulsion. 


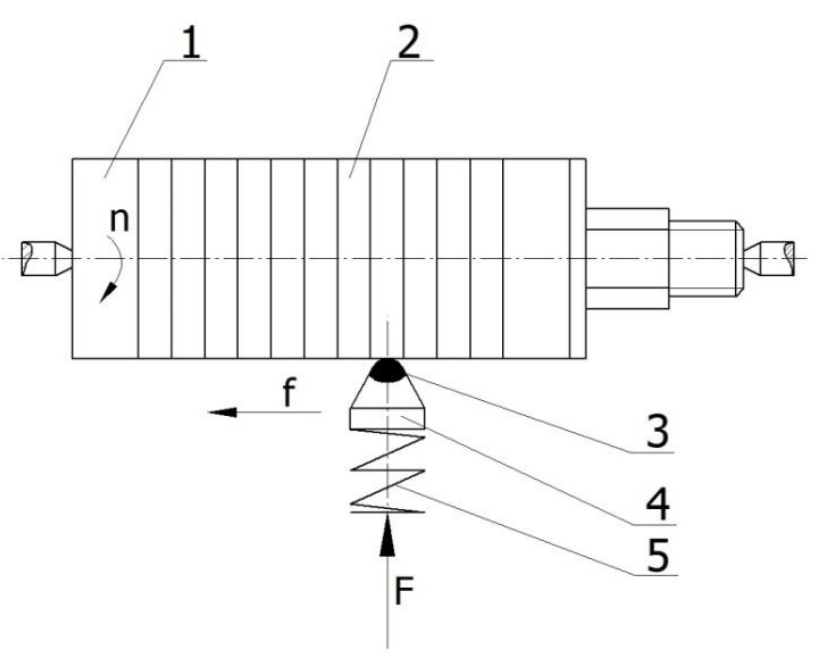

Fig. 2. Scheme of test stand for sliding burnishing: 1 - mandrel, 2 - sample, 3 - diamond tip, 4 - burnishing tool, 5 - spring

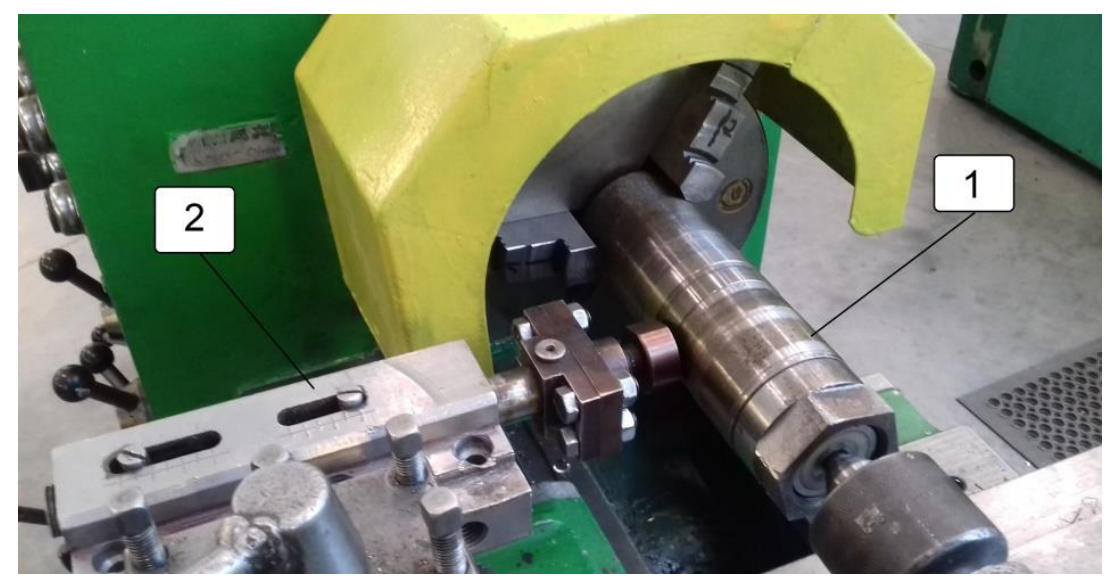

Fig. 3. Test stand for sliding burnishing: 1 - mandrel with samples, 2 - burnishing tool

The burnishing process was described with the following parameters:

- clamp force between the tool and the workpiece, $F=170 \mathrm{~N}$,

- feed rate, $f=0.05 \mathrm{~mm} / \mathrm{rev}$,

- burnishing velocity, $v=20 \mathrm{~m} / \mathrm{min}$.

Surface roughness measurements were made with the 3DT8000RC120-400 profilometer from Hommel-Etamic (according the EN ISO 4288: 1997). Surface roughness was measured along the outer cylindrical surface of the samples (perpendicular to the slide burnishing traces). The sampling length was set at $1 \mathrm{r}=0.8 \mathrm{~mm}$. The roughness parameters $R a$ and $R z$ were measured, the bearing ratio curves were determined, and the surface topography of both burnished and non-burnished samples was examined. The measurement for each sample was made six times, and six samples were tested for each slide burnishing condition.

The measurements of surface layer microhardness were performed with the LECO LM700AT microhardness tester, using the Vickers method in accordance with EN ISO 65071:2018. Microhardness was measured on perpendicular microsections of both samples subjected to burnishing in different liquid lubricants and those without slide burnishing. The microhardness measurements were taken for 6 samples (at constant processing conditions) and repeated 10 times at each depth. The indentator weight was set equal to $50 \mathrm{~g}$. 

Fig. 4.

Fatigue life measurements were made on the test stand which is schematically shown in

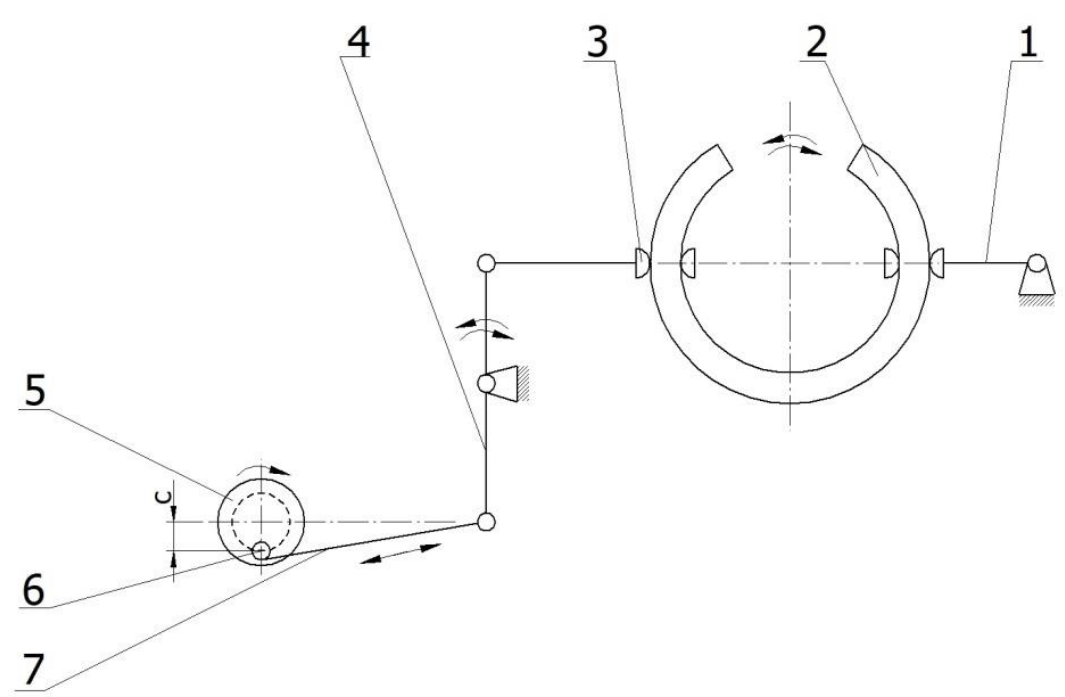

Fig. 4. Scheme of test stand for fatigue life: 1 - right holder, 2 - sample, 3 - left holder, 4 -lever, 5 - disk, 6 - mandrel, 7 - connecting-rod

Prior to the tests, the samples were cut twice along the generating line to remove fragments of the material. During the tests, the samples were cyclically deformed in such a way as to reduce their diameter. After mounting the sample (2) in holders (1) and (3), a disk (5), where in a mandrel (6) was mounted at a distance $c$ from its axis, was rotated. Said mandrel was fastened with a connecting-rod (7), the displacement of which was transmitted to the sample via a lever (4) and the holder (3), causing cyclical deformation of said sample. The number of strain-to-failure cycles was taken as a measure of fatigue life.

\section{RESULTS}

The results of surface roughness measurements are given in Figs. $5 \div 8$. As a result of slide burnishing, the average roughness $R a$ decreased by 3.5 times while the average maximum height of the profile $R z$ decreased by 2.5 times (Fig. 5). The greatest reduction in the roughness parameters $R a$ and $R z$ occurred the average roughness $R a$ decreased by 3.5 times while the average maximum height of the profile $R z$ decreased by 2.5 times when the oil with molybdenum disulfide was used as a machining medium in the burnishing process. The decrease in the $R a$ and $R z$ parameters has a positive effect on tribological wear and fatigue life.

Turning was employed as a pre-burnishing treatment, which made it possible to obtain the roughness average $R a=(1.48 \div 1.76) \mu \mathrm{m}$. Lower surface roughness can be obtained with the use of grinding. Nevertheless, due to the problems with grinding titanium alloys, such as very fast wear of the grinding wheel, this surface finishing technique was not employed. The surface roughness of Ti6A12Mo2Cr alloy after the slide burnishing process is higher than the surface roughness of X6CrNiMoTi17-12-2 stainless steel after slide burnishing ( $\mathrm{Sa}=0.153$ 
$\mu \mathrm{m})$ [23]; however, it is similar to the surface roughness of magnesium alloy samples described by $S a=(0.358 \div 0.851) \mu \mathrm{m}$, depending on the slide burnishing parameters [24].

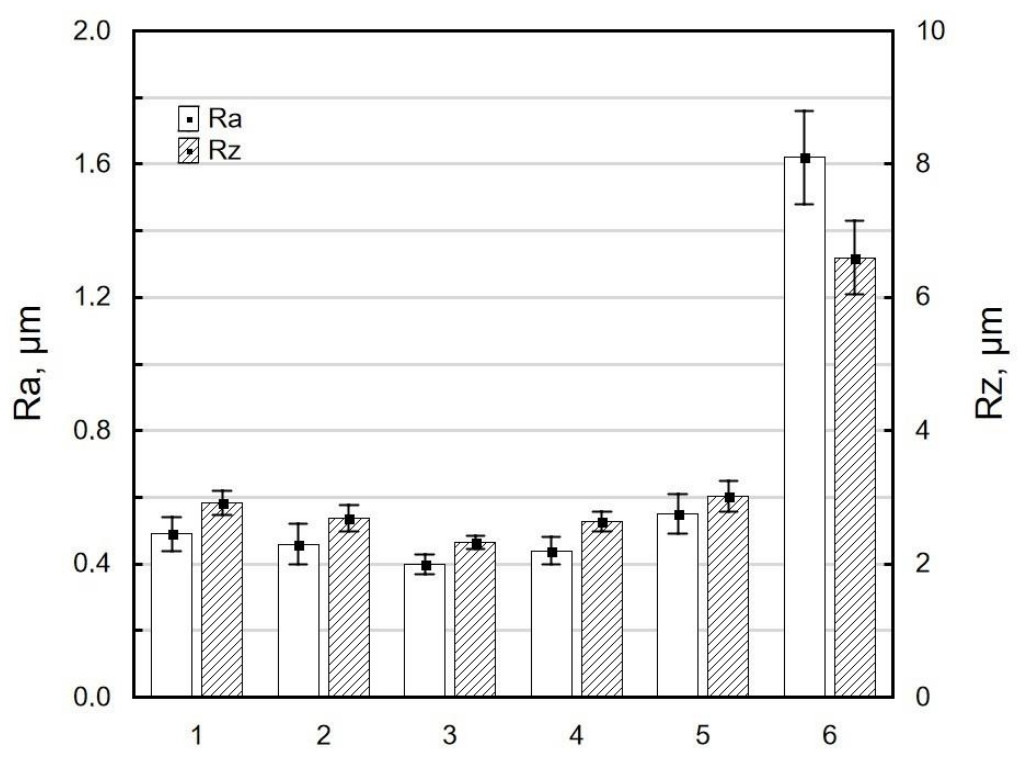

Fig. 5. Effect of slide burnishing using different machining media on the parameters Ra, Rz:1 - oil, 2 - oil with a polymethyl methacrylate solution, 3 - oil with molybdenum disulfide, 4 - oil with polymethyl methacrylate and molybdenum disulfide solutions, 5 - emulsion, 6 - non-burnished (after turning)

The bearing ratio curves obtained for the samples after turning and slide burnishing were also analyzed. Fig. 6 shows the results describing the effects of the machining method on the reduced peak height $R p k$, the core roughness $R k$ and the reduced valley depth $R v k$.

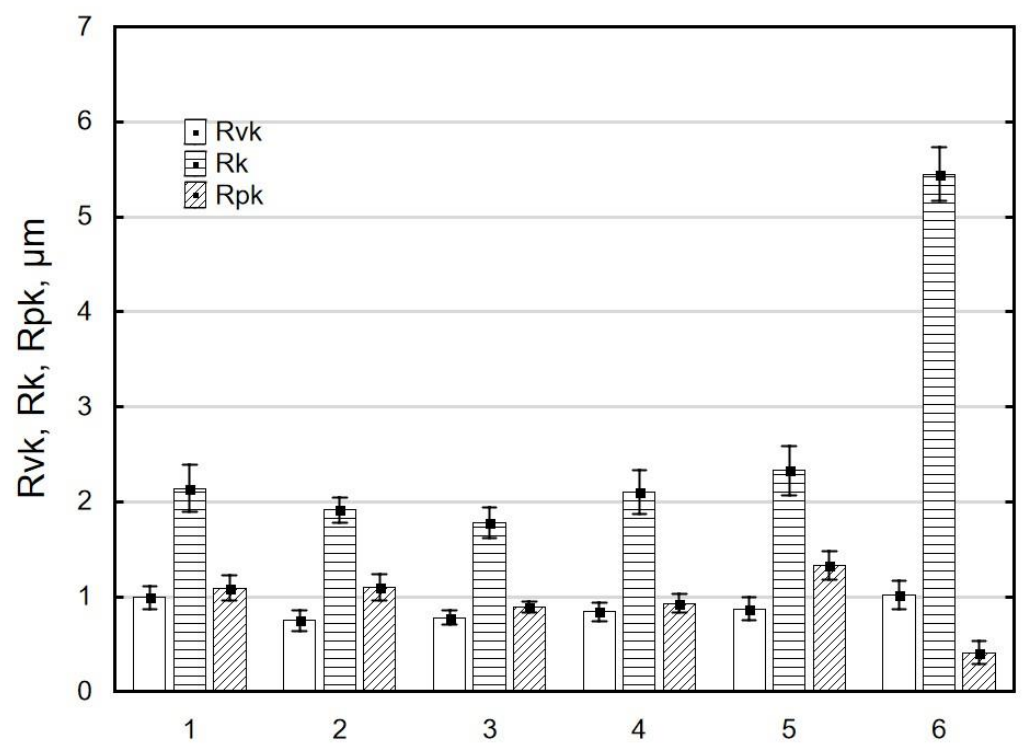

Fig. 6. Effect of slide burnishing using different machining media on the bearing ratio curve parameters Rpk, Rk, Rvk (denoted as in Fig. 5)

The slide burnishing process lead to increasing the reduced peak height $R p k$. This means that "sharp" roughness peaks are formed during burnishing. The high value of the $R p k$ parameter indicates low resistance to abrasion when the mating elements grind in. On the other hand, slide burnishing causes a 2.5 time decrease in the core roughness $R k$, which is 
desired, given the degree of wear after the grind-in period of the mating elements. The reduced valley depth $R v k$ after slide burnishing is similar to the value of this parameter obtained after turning. This means that the surface after slide burnishing and the surface after turning have a similar capacity for keeping the lubricating liquid during friction. Surface roughness after slide burnishing of Ti6Al2Mo2Cr titanium alloy was obtained at a similar level as for rolling burnishing Ti6Al4V titanium alloy [15], but with use of much smaller forces of tool influence on the workpiece. This is very important when machining low rigidity components is done.

Figs. 7 and 8 show the surface topography after turning and slide burnishing, respectively.

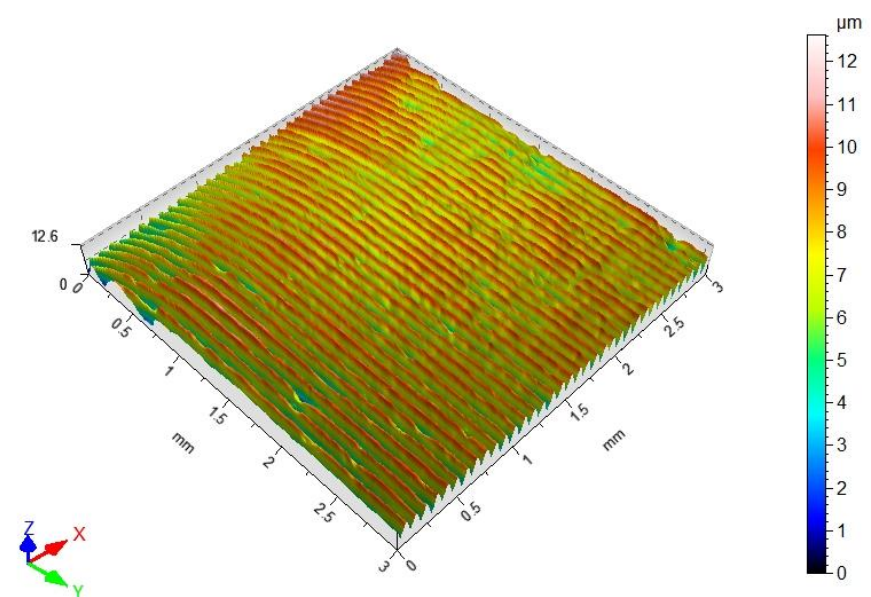

$$
\begin{gathered}
\mathrm{Sa}=1.73 \mu \mathrm{m} \\
\mathrm{Sz}=12.6 \mu \mathrm{m} \\
\mathrm{Ssk}=-0.131
\end{gathered}
$$

Fig. 7. Surface topography after turning

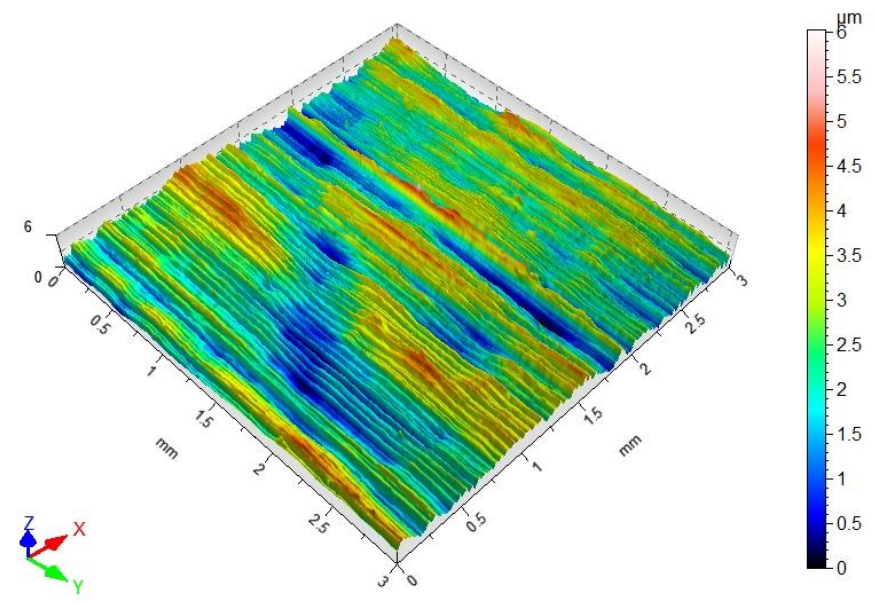

$$
\begin{gathered}
\mathrm{Sa}=0.664 \mu \mathrm{m} \\
\mathrm{Sz}=6.03 \mu \mathrm{m} \\
\mathrm{Ssk}=0.096
\end{gathered}
$$

Fig. 8. Surface topography after slide burnishing with the use oil medium

Shown in Fig. 7, the surface irregularities produced by turning have a fairly regular shape. The traces of successive passes of the cutting tool are clearly visible; they are quite rectilinear, and the distance between the peaks is equal to the feed rate during turning. After the slide burnishing process, the shape of the surface irregularities becomes more irregular 
(Fig. 8), when compared to the surface of the sample after turning. One can observe the presence of local peaks and valleys that are not related to the surface irregularities resulting from the slide burnishing kinematics. This may be associated with a high friction factor and strong adhesion between the titanium alloy sample and the diamond tip of the burnishing tool, which leads to the formation of build-up and thus to the deterioration of geometric structure of the surface.

The results of surface layer microhardness after turning and slide burnishing in different media are shown in Figs. 9 and 10, respectively.

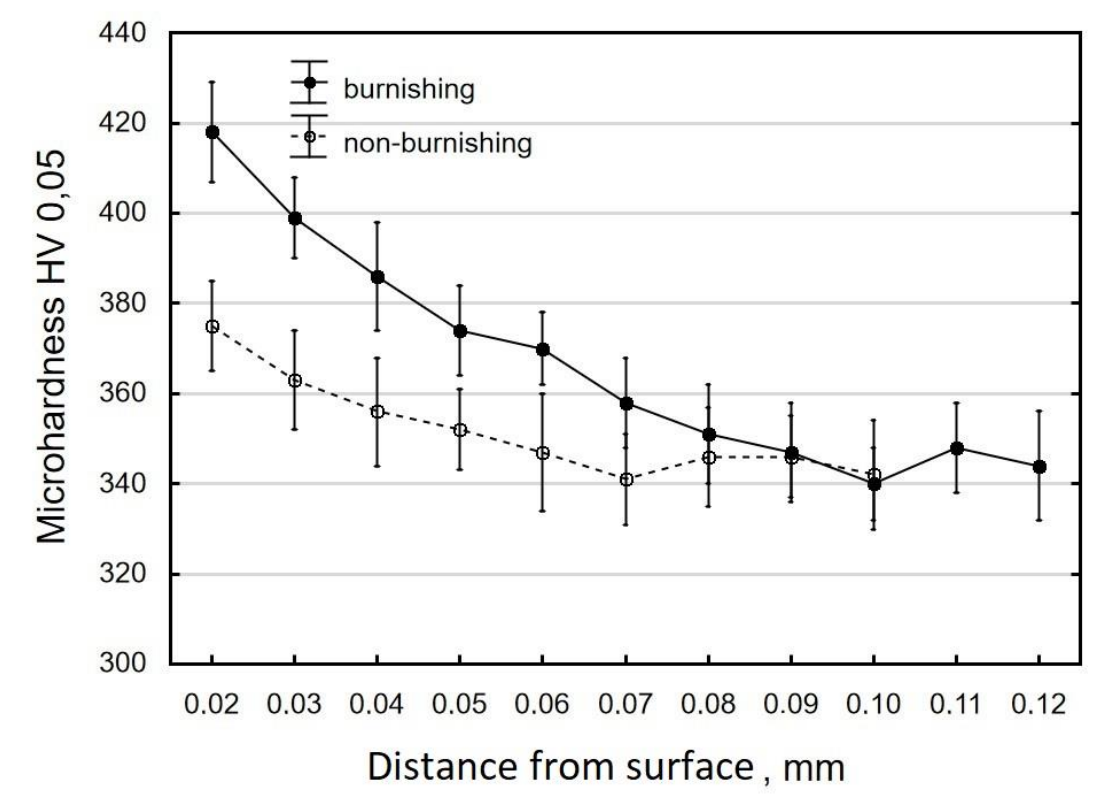

Fig. 9. Microhardness distribution of surface layer of samples after turning and slide burnishing with the use oil medium

The microhardness results demonstrate that both burnished and non-burnished samples exhibit the highest microhardness at a depth of $0.02 \mathrm{~mm}$ (Fig. 9). This is the lowest depth at which microhardness measurements were possible. The increase in microhardness at the tested depth in relation to the core microhardness of the samples slide-burnished in oil amounts to about $16 \%$. The thickness of the hardened layer after slide burnishing is about 0.1 $\mathrm{mm}$. A slight increase in the surface layer microhardness can also be observed for the samples subjected to turning.

Fig. 10 shows the surface layer microhardness at a depth of $0.02 \mathrm{~mm}$ of the samples subjected to slide burnishing in different machining media. The highest microhardness was obtained for the samples burnished in the oil containing a polymethyl methacrylate solution, which is related to the surface-active impact of this additive. At the tested depth of $0.02 \mathrm{~mm}$, the microhardness of the samples subjected to slide burnishing in the oil containing polymethyl methacrylate and molybdenum disulfide solutions is about $12 \%$ higher than that of the samples without slide burnishing (after turning). The microhardness changes after rolling burnishing Ti6Al4V alloy [15] occur at a greater depth than with sliding burnishing, but with use greater burnishing forces. Use of high burnishing forces makes it impossible machining thin-walled elements. 


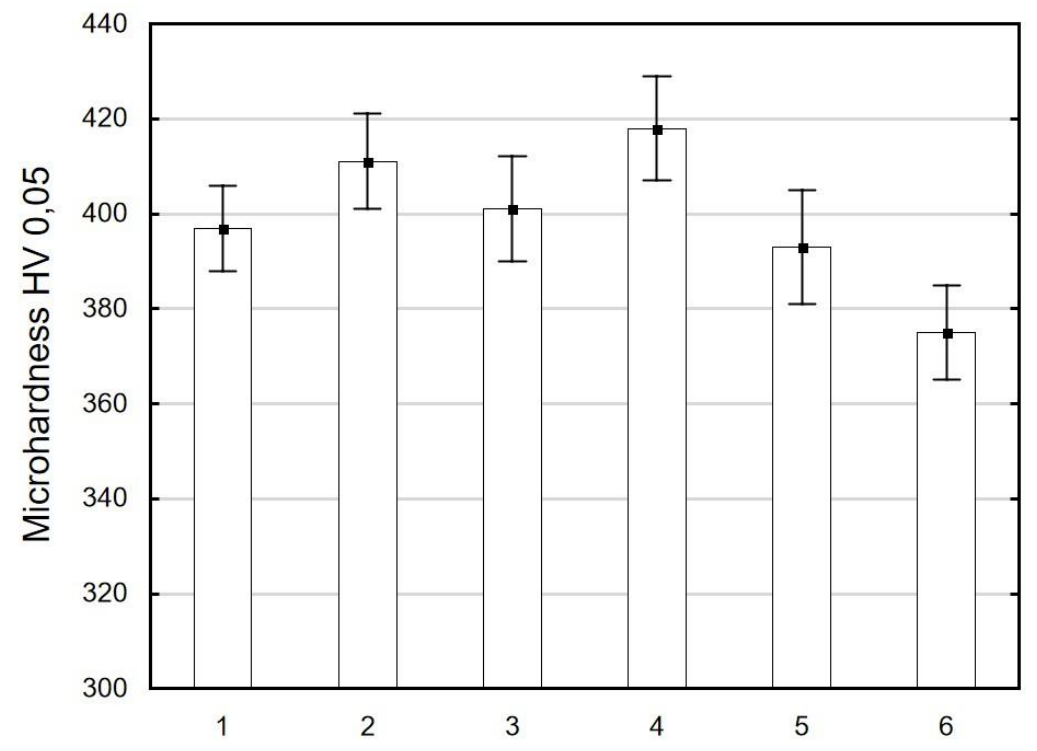

Fig. 10. Microhardness at a depth of $0,02 \mathrm{~mm}$ for samples after turning and slide burnishing machined with the use different media (denoted as in Fig. 5)

The results of fatigue life, expressed as the number of strain-to-failure cycles, obtained for the samples subjected first to turning and then to slide burnishing (after turning) indifferent machining media are compared in Fig. 11.

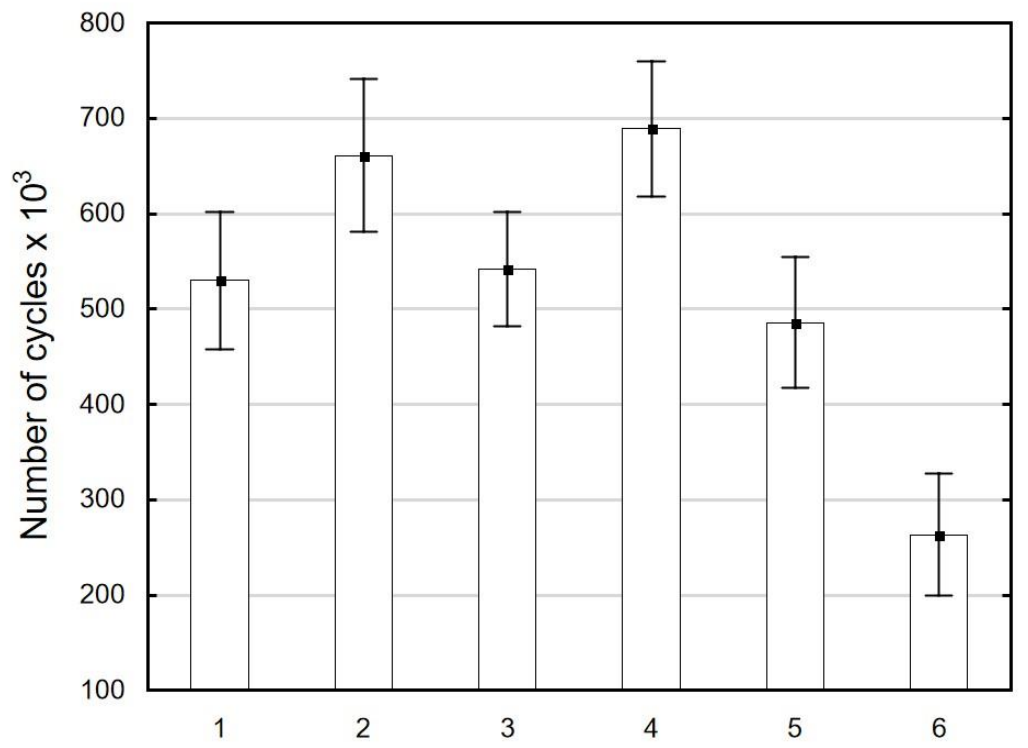

Fig. 11. Fatigue life for samples after turning and slide burnishing machined with the use different media (denoted as in Fig. 5)

It can be observed that the application of slide burnishing leads to an increase in the fatigue life of the samples. The greatest increase in fatigue life was obtained for the samples subjected to slide burnishing in the oil containing a polymethyl methacrylate solution, which confirms the beneficial effect of this additive on the burnishing effectiveness. 


\section{CONCLUSIONS}

The experimental results lead to the following conclusions:

1. The surface roughness parameters $R a$ and $R z$ of Ti6Al2Mo2Cr alloy parts decrease as a result of slide burnishing with a diamond tip tool. A more complex relationship can be observed between the slide burnishing process and the bearing ratio curve parameters. Following the application of slide burnishing, the $R p k$ parameter increases, the $R k$ parameter decreases, whereas the $R v k$ parameter does not change to any significant extent.

2. The application of slide burnishing leads to increasing the surface layer microhardness by several percent. The hardened layer depth does not exceed $0.1 \mathrm{~mm}$.

3. The changes in the surface layer properties of the tested parts induced by slide burnishing leads to increased fatigue life of these parts.

4. The effects of slide burnishing on titanium alloy depend on the medium used in this process. The use of oil containing molybdenum disulfide leads to reduced surface roughness, while the use of oil with a polymethyl methacrylate solution results in increased surface layer microhardness and fatigue life of the tested parts.

\section{REFERENCES}

1. Tsuji N., Tanaka S., Takasugi T.: Effects of combined plasma - carburizing and shot - peening on fatigue and wear properties of Ti-6Al-4V alloy. Surface \& Coatings Technology, 203 (2009) 1400-1405.

2. Lindemann J., Buque C., Appel F.: Effect of shot peening on fatigue performance of a lamellar titanium aluminide alloy. Acta Materialia, 54 (2006) 1155-1164.

3. Altenberger I.: Deep rolling - the past, the present and the future. [In:] Schulze V., Niku-Lari A.: Shot peening and other mechanical surface treatments. Proceedings of the $9^{\text {th }}$ International Conference on Shot Peening, Paris: 6-9 September (2005) 144-155.

4. Łabanowski J., Ossowska A.: Properties of duplex stainless steel surface after burnishing process. Solid State Phenomena, 165 (2010) 118-123.

5. Zaleski R., Zaleski K., Gorgol M., Wiertel M.: Positron annihilation study of aluminum, titanium, and iron alloys surface after shot peening. Applied Physics A. Materials Science \& processing, 120 (2015) 551-559.

6. Wiertel M., Zaleski K., Gorgol M., Skoczylas A., Zaleski R.: Impact of impulse shot peening parameters on properties of stainless steel surface. Acta Physica Polonica A, 132(5) (2017) 16111615 .

7. Zaleski K.: The effect of shot peening on fatigue life of parts made of titanium alloy Ti-6Al-4V. Eksploatacja i Niezawodność - Maintenance and Reliability, 4 (2009) 65-71.

8 . Ivanova S.G., Biederman R.R., Sisson R.D.: Investigation of fatigue crack initiation in Ti-6Al-4V during tensil - tensil fatigue. Journal of Materials Engineering and Performance, 11(2) (2002) 226-231.

9. Jiang X.P., Man C-S., Shepard M.J., Zhai T.: Effects of shot - peening and re - shot - peening on four - point bend behavior of Ti-6Al-4V. Materials Science and Engineering A, 468-470 (2007) $137-143$. 
10 . Yang Q., Zhou W., Niu Z., Zhang X., Wang Q., Fu X., Chen G., Li Z.: Effect of different surface asperities and surface hardness induced by shot - peening on the fretting wear behavior of Ti6Al-4V. Surface \& Coatings Technology, 349 (2018) 1098-1106.

11. Zhang X., Liu D.: Effect of shot peening on fretting fatigue of Ti811 alloy at elevated temperature. International Journal of Fatigue, 31 (2009) 881-893.

12. Zebrowski R., Walczak M., Klepka T., Pasierbiewicz K.: Effect of the shot peening on surface properties of Ti-6Al-4V alloy produced by means of DMLS technology. Eksploatacja $i$ Niezawodność - Maintenance and Reliability, 21(1) (2019) 46-53.

13. Maawad E., Bromeier H.-G., Wagner L., Sano Y., Genzel Ch.: Investigation on the surface snd near - surface characteristics of Ti-2.5Cu after various mechanical surface treatments. Surface \& Coatings Technology, 205 (2011) 3644-3650.

14 . Schuh A., Zeller C., Holmarth U., Kachler W., Wilcke G., Zeiler G., Eigenmann B., Bigoney J.: Deep rolling of titanium rods for application in modular total hip arthroplasty. Journal of Biomedical Materials Research Part B - Applied Biomaterials, 81(2) (2007) 330-335.

15 . Rotella G., Rinaldi S., Filice L.: Roller burnishing of Ti6A14V under different cooling/lubrication conditions and tool design: effects on surface integrity. The International Journal of Advanced Manufacturing Technology, (2019) 1-10 https://doi.org/10.1007/s00170-019-04631-z.

16 . Pohrelyuk I.M., Sheykin S.E., Padgurskas J., Lavrys S.M.: Wear resistance of two-phase titanium alloy after deformation- diffusion treatment. Tribology International, 127 (2018) 404-411.

17. Maheshwari A.S., Gawande R.R.: Influence of specially designed high-stiffness ball burnishing tool on surface quality of titanium alloy. Materials Today: Proceedings, 4 (2017) 1405-1413.

18. Revankar G.D., Shetty R., Rao S.S., Gaitonde V.N.: Wear resistance enhancement of titanium alloy (Ti-6Al-4V) by burnishing process. Journal of Materials Research and Technology, 6(1) (2017) 13-32.

19. Kulakowska A., Kukielka L., Kukielka K., Malag L., Patyk R., Bohdal L.: Possibility of steering of products surface layer properties in burnishing rolling process. Applied Mechanics and Materials, 474 (2014) 442-447.

20. Maximov J.T., Duncheva G.V., Anchev A.P., Ichkova M.D.: Slide burnishing - review and prospects. The International Journal of Advanced Manufacturing Technology, 104 (2019) 785801.

21 . Dzionk S., Scibiorski B., Przybylski W.: Surface texture analysis of hardened shafts after ceramic ball burnishing. Materials, 12(2) 204 (2019).

22. Tobola D., Brostow W., Czechowski K., Rusek P.: Improvement of wear resistance of some cold working tool steel. Wear 382-383 (2017) 29-39.

23. Konefal K., Korzynski M., Byczkowska Z., Korzynska K.: Improved corrosion resistance of stainless steel X6CrNiMoTi17-12-2 by sidle diamond burnishing. Journal of Materials Processing Technology, 213 (2013) 1997-2004.

24. Korzynski M., Zarski T.: Slide diamond burnishing influence on of surface stereometric structure of an AZ91 alloy. Surface \& Coatings Technology, 307 (2016) 590-595.

25. Zaleski K.: A study on the properties of surface-active fluids used in burnishing and shot peening processes. Advances in Science and Technology Research Journal, 10(31) (2016) 235-239.

26. Shchukin E.D., The influence of surface-active media on the mechanical properties of materials. Advances in Colloid an Interface Science, 123(126) (2006) 33-47. 